\title{
Design and release profile of timed-release coated granules of systemic insecticide
}

\author{
Narutoshi Kiмото, ${ }^{*},{ }^{\dagger}$ Atsushi TAKAHASHi and Kazuyuki InUBUSHi ${ }^{\dagger \dagger}$ \\ Minamata Research Center, Chisso Corp., 1-1 Noguchi-cho, Minamata, Kumamoto 867-8501, Japan \\ ${ }^{\dagger}$ Graduate School of Science and Technology, Chiba University, 648 Matsudo, Matsudo, Chiba 271-8510, Japan \\ ${ }^{\dagger}$ Graduate School of Horticulture, Chiba University, 648 Matsudo, Matsudo, Chiba 271-8510, Japan
}

(Received May 28, 2007; Accepted August 27, 2007)

\begin{abstract}
A novel timed-release system with a certain lag time (or release-suppression time) of pesticides has been developed using coated water-swelling granules including a systemic insecticide. The lag time and release profile of the insecticide are controlled by the polymer composition of the membrane that contains low-density polyethylene (LDPE) and talc, and by the core granule composition of the water-swelling material. (C) Pesticide Science Society of Japan
\end{abstract}

Keywords: timed-release, insecticide, lag time, coating, water-swelling material.

\section{Introduction}

Although fertilizers and pesticides are widely used in agriculture, they sometimes cause hazards to both humans and the environment. Recently, controlled-release granules have been studied to save on labor and to reduce the environmental load. ${ }^{1)}$

Granular fertilizers coated with polymers have been developed as controlled-release fertilizers. ${ }^{2,3)}$ Two release types of coated granular fertilizers have been developed: sustained-release type and timed-release type. ${ }^{4)}$ Timed-release technology was first developed by Fujita et al. ${ }^{5)}$ The timed-release granule (TRG) was designed to release the active ingredient at a predetermined time (lag time) after application. There have been a number of reports on water-soluble core granules used as fertilizers. ${ }^{6-8)}$

The second innovative development is single basal nursery fertilization for transplanted crops. This technology was developed by Sato et al., making the best use of TRG. ${ }^{9)}$ All the fertilizer nitrogen needed for crop growth in the field is applied by sheet placement using timed-release fertilizer, and crop seeds are sown directly on or under the timed-release fertilizer layer. This fertilizer is quite accurately release controlled so that fertilizer salt injury to crop seedlings does not occur.

\footnotetext{
* To whom correspondence should be addressed.

E-mail: n.kimoto@graduate.chiba-u.jp

Published online October 9, 2007

(C) Pesticide Science Society of Japan
}

In the field of pesticides, Sato et al. attempted to develop coated granular pesticides made up of water-soluble or volatile active ingredients coated with thermoplastic polymer composition, ${ }^{10)}$ while Nagai et al . attempted to develop timedrelease pesticides with a double layer membrane structure $^{11-14)}$; however, it was difficult to apply those technologies to slightly water-soluble active ingredients.

In a previous paper, ${ }^{15)}$ we showed a novel timed-release system with a certain lag time of pesticide release, which has been developed using polymer-coated water-swelling granules including a slightly water-soluble herbicide. In the report, the polymer membrane composition included water-permeable materials together with LDPE, and inorganic materials were used to control the lag time and the period of pesticide release.

Pest control in Japan, as in most rice-producing countries, has largely relied on insecticides. Granular insecticides are applied in the nursery box before transplanting. Insecticides are embedded into the paddy soil near the root zone and are easily absorbed by the rice plant. In this treatment, systemic insecticides are imbibed orally by sucking insects through plant tissues. Chloronicotinyl/neonicotinoid insecticides are a rapidly growing chemical class of insecticides.

We have succeeded in developing a TRG of systemic insecticides using a single layer membrane. The objective of this study was to develop timed-release technology by coating commonly used systemic insecticides with the polymer composition.

In this paper, the effect of the membrane composition of 
Table 1. Composition of core granules in timed-release granules (TRG)

\begin{tabular}{llrrrr}
\hline & & \multicolumn{2}{c}{ Core granule (wt.\%) } \\
\hline Function & Component & CG-1 & CG-2 & CG-3 & CG-4 \\
\hline Active ingredient & Imidacloprid $^{a)}$ & 2 & 2 & 2 & 70 \\
Binder/Water swelling material & Bentonite & 30 & 40 & 50 & 28 \\
Filler & Clay & 68 & 58 & 48 \\
\hline
\end{tabular}

a) Purity $70 \%$ by weight.

low-density polyethylene (LDPE) and filler, the coating ratio, and the core granule composition of the water-swelling material was examined on the release profile of imidacloprid from the TRG.

\section{Materials and Methods}

\section{Chemicals}

Imidacloprid [1-(6-chloro-3-pyridylmethyl)- $N$-nitroimidazolidin-2-ylideneamine] (purity 70\%, remainder is mineral matter, pass $75 \mu \mathrm{m}$ ) was kindly supplied by Bayer CropScience K. K. (Tokyo, Japan) as a systemic insecticide. The compound has a melting point of $143.8^{\circ} \mathrm{C}$ and a solubility of $0.610 \mathrm{~g}^{-1}$ in water at $20^{\circ} \mathrm{C}^{16)}$ Imidacloprid insecticide ${ }^{17-19)}$ is commonly used (in paddy fields) in Japan. Bentonite (HO$\mathrm{TAKA}^{\mathrm{TM}}$, particle size $<53 \mu \mathrm{m}$ ) as a water-swelling material and as a binder was supplied by HOJUN Co., Ltd. (Gunma, Japan). Clay (No. 5 Clay, particle size $<45 \mu \mathrm{m}$ ) as a filler was supplied by Takehara Kagaku Kogyo Co., Ltd. (Hyogo, Japan). These were used for the core granule materials.

A low-density polyethylene (Suntec ${ }^{\mathrm{TM}}$-LD, Melt Flow Rate $(\mathrm{MFR})=7.0 \mathrm{~g} / 10 \mathrm{~min}$.), used as water-insoluble membrane material, was supplied by Asahi Kasei Chemicals Inc. (Tokyo, Japan). Talc (magnesium silicate hydroxide, average particle size $5 \mu \mathrm{m}$ ), used as a filler, was supplied by Fuji Talc Industry Co., Ltd. (Osaka, Japan).

\section{Preparation of core granules}

The composition of the core granules is shown in Table 1. After imidacloprid was mixed with powder components, the mixed powder was kneaded with water (using a Loedige Mixer $^{\mathrm{TM}} \mathrm{M}-20$, made by Matsubo Corp.), extruded through a 0.8 mm screen (using a Twin Dome Granulator ${ }^{\mathrm{TM}}$ TDG-110, made by Fuji Paudal Co., Ltd.), and then brought to a rotating disc spheroniser (Marumerizer ${ }^{\mathrm{TM}}$ QJ-400, made by Fuji Paudal Co., Ltd.) where the extrudates were broken down into short lengths and became substantially spherical granules. The granules were then dried in a fluid-bed dryer. After sieving at $0.85 / 1.4 \mathrm{~mm}$, granules containing $1.4 \%$ by weight of imidacloprid were obtained.

\section{Preparation of coated granules}

3.1. Apparatus for coating

A schematic diagram of the experimental set up is shown in Fig. 1. It consisted of a spouted bed coater, a slurry mixer (polymer dissolution vessel), a sprayer, a heating system, and a cyclone fine particle collector. The spouted bed coater has a tower of $250 \mathrm{~mm}$ diameter, $4000 \mathrm{~mm}$ height, bottom cone of 50 -degree angle with an air exhaust inlet of $50 \mathrm{~mm}$ diameter and one fluid nozzle of $0.4 \mathrm{~mm}$ diameter for spraying coating materials.

\subsection{Coating of core granules}

Core granules of $3 \mathrm{~kg}$ were introduced into the coating apparatus via the hopper inlet wherein hot gas was flowing at a speed of $240 \mathrm{~m}^{3} \mathrm{hr}^{-1}$. A spouted bed was formed after the introduction of all granules into the tower. The membrane materials at $5 \%$ by weight tetrachloroethylene slurry were fed at the rate of $300 \mathrm{~g} \mathrm{~min}^{-1}$ to the spouted bed via the spray nozzle. The temperature of the granules was maintained at $70^{\circ} \mathrm{C}$ by controlling the hot gas temperature in the range of 68 to $72^{\circ} \mathrm{C}$. The compositions of the membrane materials are shown in Table 2.

\section{Measurement of insecticide release (dissolution test in water)}

The release of imidacloprid from granules was measured by the following method.

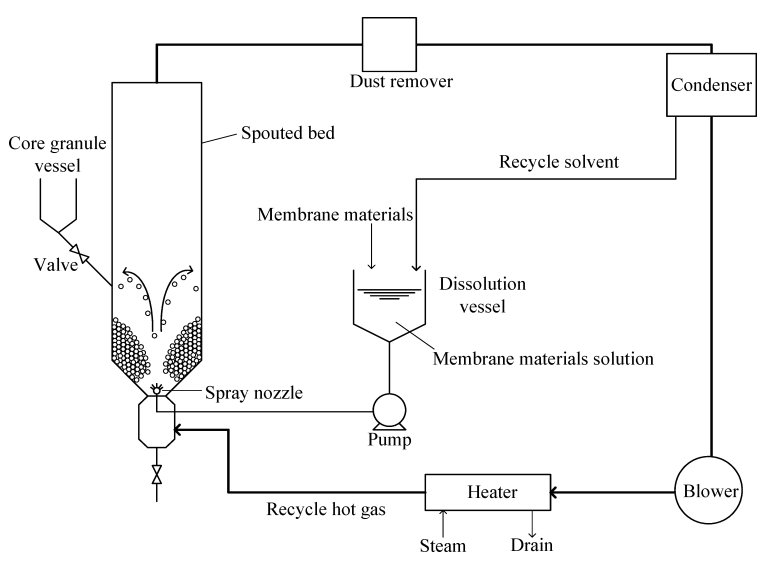

Fig. 1. Schematic diagram of the spouted bed coating system. 
Table 2. Composition of membrane materials in timed-release granules (TRG)

\begin{tabular}{|c|c|c|c|c|c|c|c|c|c|c|c|c|}
\hline \multirow[b]{2}{*}{ Materials (wt.\%) } & \multicolumn{12}{|c|}{ Formulation code } \\
\hline & TRG-1 & TRG-2 & TRG-3 & TRG-4 & TRG-5 & TRG-6 & TRG-7 & TRG-8 & TRG-9 & TRG-10 & TRG-11 & TRG-12 \\
\hline $\mathrm{LDPE}^{a)}$ & 19 & 21 & 23 & 25 & 27 & 27 & 27 & 27 & 24 & 24 & 24 & 24 \\
\hline Talc & 81 & 79 & 77 & 75 & 73 & 73 & 73 & 73 & 76 & 76 & 76 & 76 \\
\hline Core granule & CG-4 & CG-4 & CG-4 & CG-4 & CG-4 & CG-4 & CG-4 & CG-4 & CG-1 & CG-2 & CG-3 & CG-4 \\
\hline Coating ratio ${ }^{b)}$ & 20 & 20 & 20 & 20 & 10 & 14 & 17 & 20 & 20 & 20 & 20 & 20 \\
\hline
\end{tabular}

${ }^{a)}$ Low-density polyethylene. ${ }^{b)}$ Coating ratio (wt.\%) $=($ membrane weight $) /($ TRG weight $)$.

One coated granule was placed in each of 100 test tubes (diameter $12 \mathrm{~mm}, 72 \mathrm{~mm}$ high) filled with $1.5 \mathrm{ml}$ of water. Each tube was capped and immersed in a water bath maintained at $20^{\circ} \mathrm{C}$. Visual observations of the coated granules were made to detect the release of the insecticide from the granules. Imidacloprid release of coated granules was determined by the number of burst granules under the assumption that burst granules released all imidacloprid in water. Cumulative release means cumulative burst granule number of coated granules. Visual observations were carried out everyday from the time the granules were soaked in water. In this work, we stated a $0-10 \%$ release period of imidacloprid as the lag time.

Moreover, it was confirmed that imidacloprid did not penetrate the membrane as determined by high performance liquid chromatography.

\section{Results and Discussion}

\section{Design of TRG}

TRG has a single-layered structure of a core granule and membrane, as shown in Fig. 2. Core granules consist of the active ingredient, swelling material, and inorganic filler. Membrane materials are a water-insoluble polymer and inorganic filler.

\section{Effect of amount of LDPE on release profile of imida-} cloprid

The relationship between the rate of imidacloprid release and

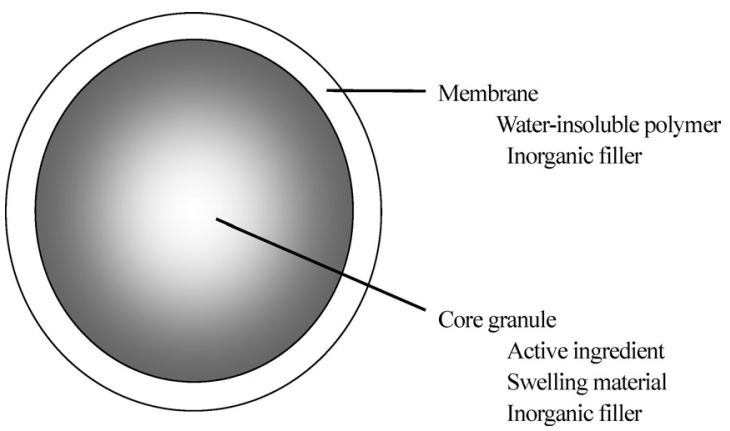

Fig. 2. Schematic structure of the timed release granules (TRG). the LDPE (19-25\% by weight) content in the membrane was investigated. The amount of membrane was fixed at 20\% (by weight). It was found that the lag time became longer and the release rate of imidacloprid decreased along with the increase of LDPE content (Fig. 3). Lag times and LDPE content were fitted by linear regression $[\mathrm{Y}=4.1 \mathrm{X}-67.2$, $\mathrm{Y}$ : lag time (days), $\mathrm{X}$ : the LDPE content (wt.\%), coefficient of determination: 0.961]. There was good linear correlation between the LDPE content in the membrane and the total release time $[\mathrm{Y}=6.85 \mathrm{X}-109.95, \mathrm{Y}$ : total release time (days), $\mathrm{X}$ : the amount of LDPE (wt.\%), coefficient of determination: 0.998]. From the above result, it appears that the lag time and total release time could be controlled by the LDPE content in the membrane.

It has been shown by Tashima et al. ${ }^{20)}$ that the lag time and release rate could be controlled by the white carbon content in the water-insoluble polymer membrane. In this study, the change in lag time may be related to water permeability into the TRG.

\section{Effect of the amount of membrane on release profile of imidacloprid}

The relationship between the rate of imidacloprid release and the amount of the membrane (10-20\% by weight) contained

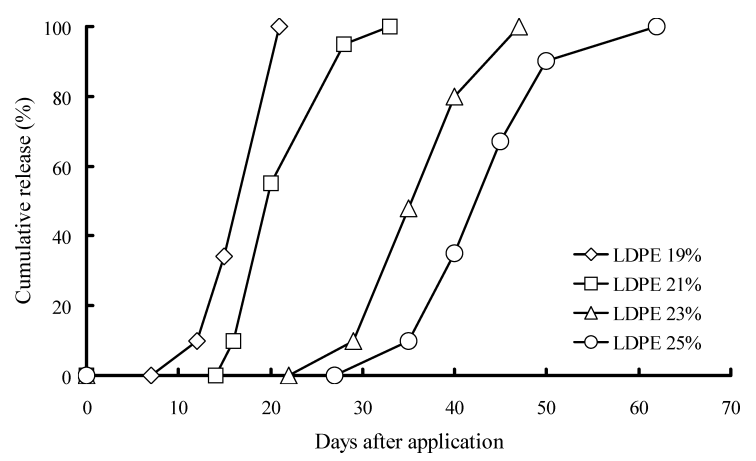

Fig. 3. Effect of LDPE content in membrane materials on release profile. Formulation codes TRG-1, TRG-2, TRG-3 and TRG-4 were used for LDPE of $19 \%, 21 \%, 23 \%$, and $25 \%$ in the membrane, respectively. 


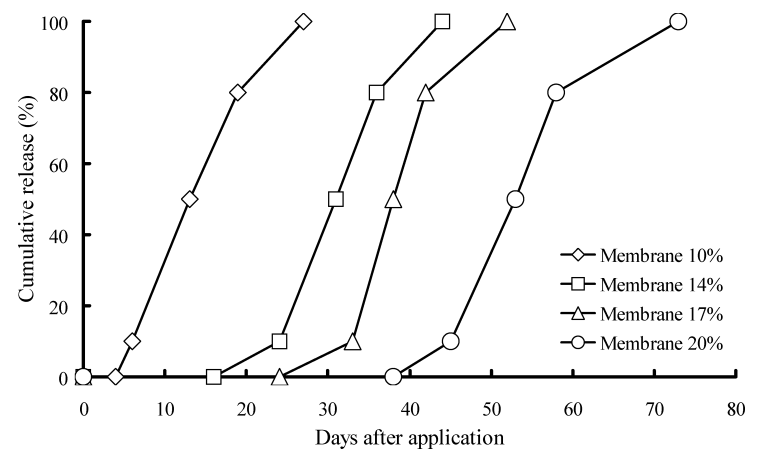

Fig. 4. Effect of the amount of membrane material in TRG on release profile. Formulation codes TRG-5, TRG-6, TRG-7 and TRG- 8 were used for the membrane of $10 \%, 14 \%, 17 \%$, and $20 \%$ in TRG, respectively.

in the coated granules was investigated. The LDPE content in the membrane was fixed at $27 \%$ (by weight). It was found that the lag time became longer depending upon the increase of the membrane amount and that the release of imidacloprid also became later (Fig. 4). Lag times and the amount of the membrane were fitted by linear regression $[Y=3.84 X-31.49$, Y: lag time (days), X: amount of membrane (wt.\%), coefficient of determination: 0.994]. There was good linear correlation between the amount of membrane in the coated granules and the total release time $[\mathrm{Y}=3.88 \mathrm{X}-11.69, \mathrm{Y}$ : total release time (days), X: amount of membrane (wt.\%), coefficient of determination: 0.990]. From the above result, it appears that the lag time and total release time could be controlled by the amount of membrane contained in the coated granules.

\section{Effect of amount of bentonite on release profile of imi- dacloprid}

The relationship between the rate of imidacloprid release and the amount of bentonite (30-70\% by weight) contained in the core granules was investigated. The amount of LDPE was fixed at $20 \%$ (by weight) in the membrane. It was found that the lag time became longer and that the total release of imidacloprid became later depending upon the decrease of bentonite content (Fig. 5). Lag times and the amount of bentonite were fitted by an exponential curve $\left[Y=1175 \mathrm{X}^{-1.0815}\right.$, Y: lag time (days), X: the amount of bentonite (wt. \%), coefficient of determination: 0.934]. There was good exponential correlation between the amount of bentonite in the core granules and the total release time $\left[Y=72204 \mathrm{X}^{-1.9344}, \mathrm{Y}\right.$ : total release time (days), X: the amount of bentonite (wt.\%), coefficient of determination: 0.923$]$. From the above result, it appears that the lag time and total release time could be controlled by the bentonite content in the core granules.

It has been shown by Nagai et al. ${ }^{11)}$ that a TRG could be prepared by a double-layered membrane composed of waterswelling material (inside layer) and water-insoluble polymer (outside layer). It has been shown by Tashima et al. ${ }^{20)}$ that changes in both lag time and release rate were considered to

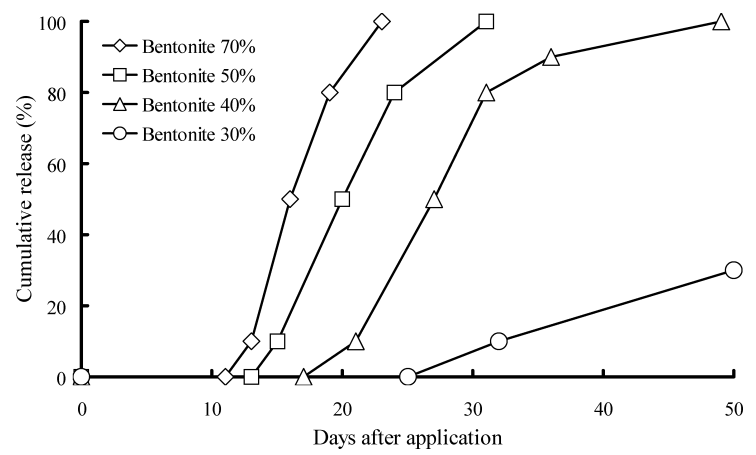

Fig. 5. Effect of bentonite content in core granules on release profile. Formulation codes TRG-9, TRG-10, TRG-11 and TRG-12 were used for bentonite $30 \%, 40 \%, 50 \%$, and $70 \%$ in core granules, respectively.

be related to water permeability into the TRG and the tensile strength of the membrane. In a previous paper, ${ }^{15)}$ we showed polymer membrane compositions, including LDPE and filler, for the control of lag time, and that the membrane without filler did not burst. In this study, there was a water-swelling material in the core granules, and the membrane including LDPE and filler was single-layered. The change in lag time was considered to relate to the strength of the membrane and the water-swelling material of the core granules.

\section{Effect of temperature on release profile}

Release measurement was performed under constant temperatures of $15,20,25$, and $35^{\circ} \mathrm{C}$ (Fig. 6). As the temperature increased, the lag time was shortened and release rate increased. As a result, there was a negative relationship between the temperature and lag time, indicating temperature dependency of lag time in the range of $15-35^{\circ} \mathrm{C}$ (Fig. 7). We saw from Fig. 7 that the release velocity nearly doubled by the temperature increase of $10^{\circ} \mathrm{C}$. This relation was referred to simply as the temperature coefficient $\left(\mathrm{Q}_{10}\right)=2 . \mathrm{Q}_{10}$ is a measure of the rate of change of a biological or chemical system as a consequence of increasing the temperature by $10^{\circ} \mathrm{C} .^{21)}$ It has been shown by Fujita $e t a l^{7)}$ and Tashima et al. ${ }^{22)}$ that the release profile of active ingredients from coated granules was influ-

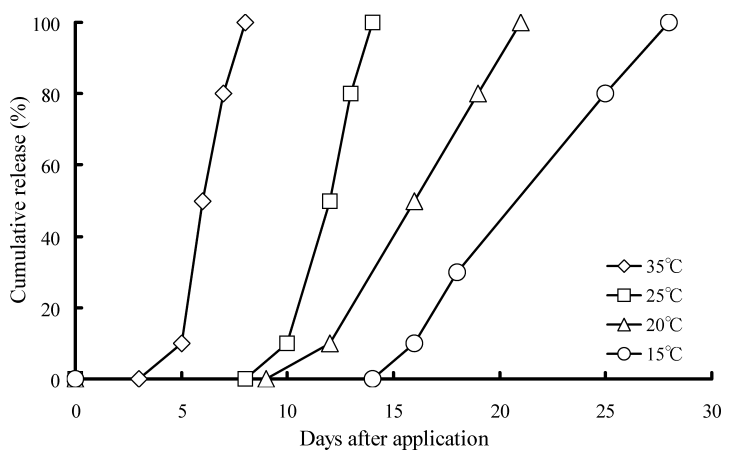

Fig. 6. Effect of water temperature on release profile. LDPE content in the membrane was fixed at $19 \%$ by weight. 


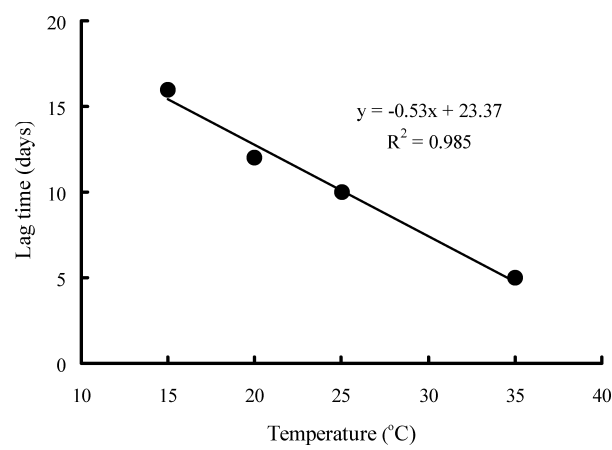

Fig. 7. Effect of water temperature on the lag time of imidacloprid release. LDPE content in the membrane was fixed at $19 \%$ by weight.

enced by temperature. These results are similar to this study.

In paddy fields, water temperature changes and consequently the release profile of active ingredients varies. On the other hand, TRG with various release profiles can be made by changing the LDPE/talc ratio of the membrane, the coating ratio, and the amount of bentonite contained in the core granules. Therefore, TRG composition should be optimized to achieve the highest rice disease preventive effects.

\section{Conclusion}

A new concept of timed release of systemic insecticides was investigated. Coated granules utilizing LDPE and talc in the single layer membrane and bentonite in core granules showed a timed-release function, i.e. lag time was observed in the release profile and the systemic insecticide was released rapidly after the lag time. Lag time could be controlled by LDPE/talc ratios in the membrane and the amount of membrane, LDPE and bentonite in the TRG. The release profile of imidacloprid from TRG was influenced by temperature.

\section{References}

1) S. Shoji and H. Kanno: Fertil. Res. 39, 147-152 (1994).

2) D. W. Rindt, G. M. Bluin and J. G. Getsinger: J. Agric. Food Chem. 16, 773-778 (1968).
3) G. Pipko, S. Manor, K. Haim, M. Ziv and K. Motzkin: US Pat. No.4936897 (1990).

4) S. Shoji(ed.): "Meister: Controlled Release Fertilizer: Properties and Utilization," Konno Printing, Sendai, Japan, pp. 13-15, 1999.

5) T. Fujita and S. Yoshida: US Pat. No.6193775 B1 (2001).

6) T. Fujita, C. Takahashi, M. Ohshima, T. Ushioda and H. Shimizu: US Pat. No. 4019890 (1977).

7) T. Fujita, C. Takahashi, S. Yoshida and H. Shimizu: US Pat. No. 4369055 (1983).

8) A. Shaviv and R. L. Mikkelsen: Fertil. Res. 35, 1-12 (1993).

9) T. Sato and H. Chinen: Jpn. Kokai Tokkyo Koho JP 7-236352 (1995) (in Japanese).

10) C. Sato, M. Watanabe, Y. Nakamura and S. Okuda: Jpn. Kokai Tokkyo Koho JP 57-126402 (1982) (in Japanese).

11) H. Nagai, A. Okazaki and K. Nitani: Jpn. Kokai Tokkyo Koho $J P$ 6-9303 (1994) (in Japanese).

12) H. Nagai, A. Okazaki and K. Nitani: Jpn. Kokai Tokkyo Koho JP 6-9304 (1994) (in Japanese).

13) H. Nagai, A. Okazaki and K. Nitani: Jpn. Kokai Tokkyo Koho JP 6-72805 (1994) (in Japanese).

14) H. Nagai, A. Okazaki and K. Nitani: Jpn. Kokai Tokkyo Koho $J P$ 6-80514 (1994) (in Japanese).

15) N. Kimoto, Y. Kutsuzawa and K. Inubushi: J. Pestic. Sci. 32, 243-248 (2007).

16) Y. Uesugi, M. Ueji and M. Koshioka (eds.): "Pesticide Data Book 3rd Edition," Soft Science Publications, Tokyo, p. 224, 1997.

17) S. Kagabu, K. Moriya, K. Shibuya, Y. Hattori, S. Tsuboi and K. Shiokawa: Biosci. Biotechnol. Biochem. 56, 362-363 (1992).

18) K. Moriya, K. Shibuya, Y. Hattori, S. Tsuboi, K. Shiokawa and S. Kagabu: Biosci. Biotechnol. Biochem. 56, 364-365 (1992).

19) S. Kagabu, K. Yokoyama, K. Iwaya and M. Tanaka: Biosci. Biotechnol. Biochem. 62, 1216-1224 (1998).

20) S. Tashima, S. Shimada, K. Matsumoto, R. Takeda and T. Shiraishi: J. Pestic. Sci. 25, 379-384 (2000).

21) T. W. Hegarty: Nature 243, 305-306 (1973).

22) S. Tashima, S. Shimada, K. Matsumoto, R. Takeda and T. Shiraishi: J. Pestic. Sci. 26, 244-247 (2001). 